\title{
La recepción de la doctrina de los indiferentes en Epicteto
}

\author{
Rodrigo Sebastián BRAICOVICH \\ Universidad Nacional de Rosario, Argentina \\ rbraicovich@gmail.com
}

\begin{abstract}
RESUMEN: Este trabajo tiene por objetivo analizar la posición de Epicteto ante la doctrina estoica de los indiferentes, y en especial respecto a la distinción entre indiferentes preferidos y dispreferidos. Sugiero que, para entender la posición del autor es preciso recurrir a la distinción entre aquello que depende y aquello que no depende de nosotros, pues considero que los pasajes aquí presentados avalan la idea de que Epicteto habría rechazado firmemente la distinción entre indiferentes preferidos y dispreferidos. Sugeriré, además, que ciertos pasajes que parecen a primera vista contradecir esta conclusión pueden ser perfectamente explicados sin necesidad de suponer que el autor otorga algún valor a lo indiferente.
\end{abstract}

\section{Epictetus' Reception of the Doctrine of Preferred Indifferents}

\begin{abstract}
This paper analyzes Epictetus' position on the Stoic doctrine of indifferents and in particular on the distinction between preferred and dispreferred indifferents. I suggest that in order to understand the author's position it is necessary to turn to the distinction between that which depends on us and that which doesn't, as the passages presented here support the idea that Epictetus firmly rejected the distinction between preferred and dispreferred indifferents. I will further suggest that certain passages which might at first glance seem to contradict this conclusion can be perfectly explained without assuming necessarily that the author granted any value whatsoever to indifferents.
\end{abstract}

PALABRAS ClAVE: Epicteto, estoicismo, indiferentes preferidos, indiferentes dispreferidos.

KEYWORDS: Epictetus, stoicism, preferred indifferents, dispreferred indifferents.

FECHA DE RECEPCIÓN: 1 de diciembre de 2011.

FECHA DE ACEPTACIÓN: 13 de agosto de 2012. 



\title{
La recepción de la doctrina de los indiferentes en Epicteto
}

\author{
Rodrigo Sebastián BRAICOVICH
}

La doctrina de los indiferentes en el estoicismo antiguo

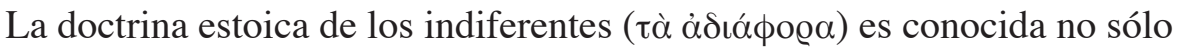
por su carácter polémico, sino también por la centralidad que asume en el sistema filosófico del estoicismo antiguo. La formulación básica de esta doctrina se encuentra en Estobeo:

Entre las cosas existentes, unas son bienes, otras males y otras indiferentes. Bienes son cosas de este tipo: prudencia, templanza, justicia, valentía y todo lo que es virtud y participa de ella. Males, en cambio, son cosas de este tipo: imprudencia, intemperancia, injusticia, cobardía y todo lo que es vicio o participa de él. Indiferentes, por su parte, son cosas de esta índole: vida-muerte, reputación-falta de reputación, placer-dolor, riqueza-pobreza, salud-enfermedad y lo similar a esto.

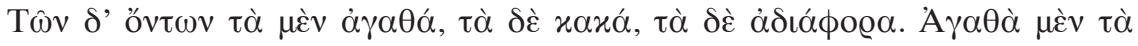

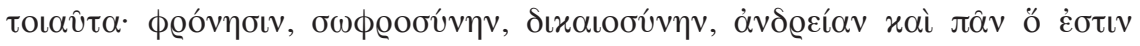

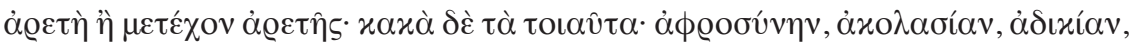

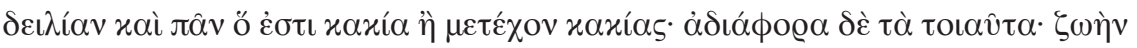

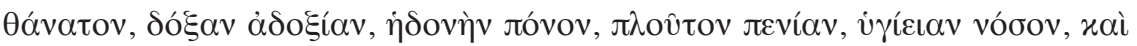

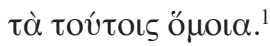

Podemos en principio extraer a partir de las fuentes que se conservan del estoicismo antiguo tres elementos fundamentales para la comprensión del concepto de lo indiferente: i) los indiferentes no son condición ni suficiente ni necesaria de la virtud: la posesión de riquezas materiales, por ejemplo, no sólo no garantiza la posesión de la virtud sino que tampoco es uno de los componentes necesarios para alcanzarla. ${ }^{2}$ (De modo inverso, así como los indiferentes no pueden garantizar el ejercicio de la virtud,

\footnotetext{
${ }^{1}$ Stob., Ecl., 2, 57, 19-58, 4 W (traducción de M. Boeri).

${ }^{2}$ Cf. D. L., 7, 104-5; SVF, 3,104; LS, 58B.
} 
tampoco pueden obstaculizarlo. ${ }^{3}$ ) ii) Lo indiferente es tal porque, a diferencia de la virtud y del vicio, no puede beneficiar ni dañar al sujeto. ${ }^{4}$ iii) Existen ciertas cosas que pueden, a diferencia de la virtud y el vicio, ser usadas tanto virtuosa como viciosamente (v. g., puedo hacer un uso racional o irracional de mis posesiones o de la influencia que poseo sobre los demás en virtud de mi reputación); dado que tales cosas pueden ser usadas de ambas formas no pueden ser en sí mismas ni virtuosas ni viciosas; deben ser, por lo tanto, indiferentes. ${ }^{5}$

Éste no es, sin embargo, el final de la historia, dado que el concepto de lo indiferente es tan central ${ }^{6}$ a la reflexión ética del estoicismo antiguo

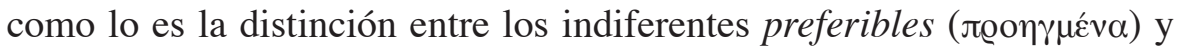

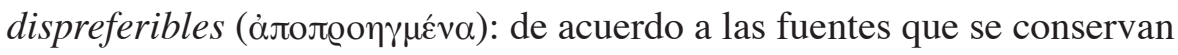
relativas al período antiguo de la escuela, si bien la gloria, las riquezas, la vida o la muerte, etc., son todas ellas indiferentes en relación con la consecución de la buena vida, de la vida virtuosa, la doctrina de los indiferentes no se agota en esta distinción primaria, sino que supone la posibilidad de calificar a los indiferentes de acuerdo al valor $(\dot{\alpha} \xi i \alpha)$ o disvalor ( $\dot{\alpha} \pi \dot{\xi} \xi \dot{\alpha} \alpha)$ que los mismos poseen. Aquello que posea mucho valor (como la vida o la salud) será preferible, y aquello que posea mucho disvalor será dispreferible. ${ }^{7}$ El registro de Estobeo nos permite asignar una característica

${ }^{3}$ Esta conclusión (perfectamente lógica si partimos del concepto de lo indiferente) es la que permitirá a Séneca, siglos más tarde, realizar una apología de sus cuantiosos bienes personales apelando precisamente a la doctrina de los indiferentes. Vid. Motto, 1996.

${ }^{4}$ Cf. D. L., 7, 101, 3; LS, 58A.

${ }^{5}$ Cf. D. L., 7, 101, 3; LS, 58A. Como se hace evidente, ninguno de los tres elementos mencionados demuestra que la clase de los indiferentes esté constituida por objeto alguno, sino que son meramente explicitaciones de algunas de las características de lo indiferente en cuanto tal. Para que constituyeran argumentos que demostraran que las riquezas, etc., son efectivamente indiferentes, sería necesario demostrar que (i) ninguna de las cosas consideradas por los estoicos como indiferentes son necesarias ni suficientes para la virtud, (ii) que ninguna de ellas puede beneficiarnos ni dañarnos y (iii) que todas ellas pueden ser usadas tanto virtuosa como viciosamente.

${ }^{6}$ Nicholas White nos previene correctamente de suponer que la distinción entre indiferentes preferibles y dispreferibles constituiría una elaboración posterior a la distinción primigenia entre virtud/vicio e indiferentes, destinada a responder a las críticas de escuelas rivales en relación a la ausencia de una guía adecuada para la acción a la que conduciría la doctrina de los indiferentes. Cf. White, 1990, p. 45.

${ }^{7}$ Los estoicos suponen, desde un inicio, que este valor asignado a lo preferible no es equivalente al bien propio de la virtud: afirmar que la salud posee "mucho valor" no impli- 
adicional al concepto de lo preferible que será importante al momento de definir la posición de Epicteto en relación a esta problemática, a saber, que existen ciertas cosas que son "acordes con la naturaleza" ( $x \alpha \tau \grave{\alpha}$

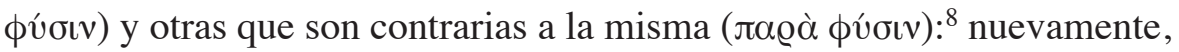
la vida y la salud, por ejemplo, son acordes con la naturaleza, mientras que sus contrarios no lo son.

El horizonte que se abre así ante los ojos es mucho más complejo de lo que inicialmente parecía afirmar la doctrina de los indiferentes: la virtud no es el único objetivo al cual debemos aspirar ni el vicio lo único que debemos evitar; existe un rango infinito de entes y acontecimientos en relación con los cuales debemos ejercitar nuestra capacidad de elección

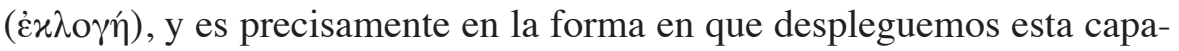
cidad en donde se hará evidente nuestra sabiduría e ignorancia. Desde un inicio, la elección de la que se trata en este caso no es en absoluto la elección de lo bueno, lo cual no puede, en rigor, ser elegido; apelando a la analogía tomada de la vida política: "en la corte, el rey [i. e., la virtud] no se encuentra entre los preferidos sino que preferidos son quienes están ubicados por debajo de él". ${ }^{\circ}$

Una de las críticas más célebres a la doctrina de los indiferentes preferidos fue realizada por Aristón de Quíos, un alumno del propio Zenón, fundador de la escuela:

(i) Aristón de Quíos dijo que la salud y todo lo que es como ella no es un indiferente preferido. Pues llamarla "indiferente preferido" es equivalente (íøov) a considerarla un bien, y la diferencia es casi sólo nominal. (ii) En efecto, por lo general los indiferentes entre virtud y vicio no se distinguen en nada ni son algunos de ellos por naturaleza preferidos y otros dispreferidos, sino que, debido a distintas circunstancias ( siones, ni las cosas llamadas preferidas se tornan invariablemente ( $\pi \alpha ́ v \tau \omega \varsigma)$

ca asumir que sea buena sin más, en tanto ese valor no la priva de su carácter de indiferente. Sobre el carácter extremadamente problemático de esta suposición, véase White, 1990.

${ }^{8}$ Una diferencia importante entre ambos criterios es la dificultad de establecer mediante el concepto de lo acorde con la naturaleza una gradación análoga a la que registra el propio Estobeo en relación a la idea de valor/disvalor: mientras que la idea de que ciertas cosas tendrían más valor que otras parece completamente intuitiva, se vuelve difícil pensar la posibilidad de que $x$ sea más acorde con la naturaleza que $y$. Cf. Stob., Ecl., 2., 84, 18-85, 11 W; SVF, 3,128; LS, 58E.

${ }^{9}$ Stob., Ecl., 2, 84, 18-85, 11 W; SVF, 3,128; LS, 58E (traducción de M. Boeri). 


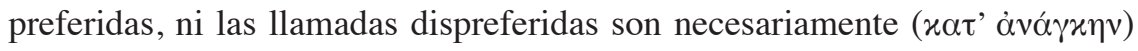
dispreferidas. Ahora bien, si las personas sanas deben servir a un tirano y por esa razón deben ser destruidas, en tanto que los enfermos, al ser liberados de su servidumbre, al mismo tiempo están exentos de la destrucción, el sabio elegirá en esta ocasión estar enfermo más que estar sano. Y así, ni la salud es algo absolutamente preferido ni la enfermedad algo dispreferido. [...] Así en las cosas que se encuentran entre virtud y vicio no hay una preferencia

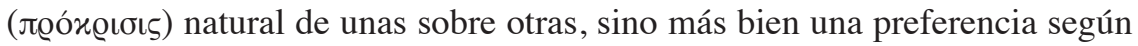
las circunstancias. ${ }^{10}$

Este registro de Sexto Empírico recoge dos posiciones diferentes e incompatibles en relación con la noción de lo preferido, ambas relevantes para la comprensión de la posición posterior de Epicteto. La posición que comienza en (ii) no ataca la noción en sí de lo indiferente, sino que pone en cuestión el hecho de que existan cosas que sean incondicionalmente ( $\pi \alpha ́ v \tau \omega \varsigma)$ preferibles. Esto no significa, como se hace evidente, negar que cada uno de los indiferentes posea un valor, sino simplemente hacer a ese valor condicional o relativo a las circunstancias (bajo ciertas condiciones, ciertas cosas son efectivamente preferibles). Desde esta perspectiva, la posición de Aristón ciertamente no parece demasiado radical ni tampoco parece representar algo que Zenón no habría estado dispuesto a conceder. La alternativa restante $(i)$, por el contrario, cuestiona en forma explícita el concepto mismo de lo indiferente, apoyándose en la problematicidad de la distinción estoica entre " $x$ es bueno" $y$ " $x$ tiene cierto valor". Reconocer a $x$ como preferible implica asignarle valor; si lo hacemos, supone Aristón, $x$ deja de ser indiferente y la distinción entre lo indiferente preferido y lo bueno en sentido estricto deviene una mera diferencia de nombres. ${ }^{11} \mathrm{La}$ pregunta acerca de cuál de estas dos alternativas representa la posición definitiva de Aristón puede ser respondida atendiendo a la reputación de radicalidad y heterodoxia de la que gozaron sus reflexiones y tomando en cuenta una serie de pasajes complementarios: “Aristón de Quíos [...]

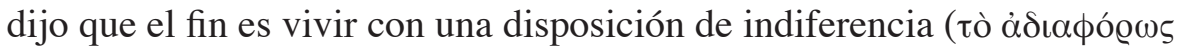
É $\chi 0 v \tau \alpha)$ con respecto a lo intermedio entre la virtud y el vicio, sin renun-

${ }^{10}$ S. E., M., 2, 64-7; SVF, 1, 361; LS, 58F (traducción de M. Boeri).

${ }^{11}$ Afirmar que el valor de los indiferentes preferibles es un valor secundario o que se

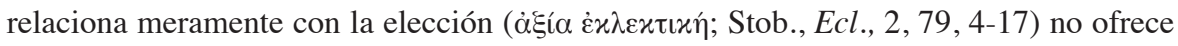
una salida al problema, dado que la asignación de cualquier tipo de valor despoja a lo preferible de su carácter de indiferente. 
ciar a dicho estado al admitir grados entre ambos, sino estando igualmente dispuesto (غ̇лí⿴囗ऽ) en relación a todas ellas". ${ }^{12}$ Este pasaje inclina la balanza en forma decisiva en favor de la segunda alternativa: no existe diferencia alguna entre los indiferentes; la distinción entre indiferentes preferidos y dispreferidos es ilegítima; debemos exhibir una actitud de indiferencia ante todo aquello que no es virtud o vicio.

Las consecuencias prácticas de esta posición, sin embargo, son evidentes, y pueden ser sintetizadas a partir de Cicerón: "si afirmáramos que [la diferencia entre las cosas] no existe, toda la vida se confundiría, como en Aristón, y no se encontraría ninguna función o tarea para la sabiduría, al no existir absolutamente ninguna diferencia entre las cosas necesarias para llevar adelante la vida ni ser indispensable el empleo de una selección". ${ }^{13}$ Amén de la pertinencia de la crítica de Cicerón (a través de Catón) a la posición de Aristón, ${ }^{14}$ este pasaje pone de relieve el carácter central y la absoluta relevancia que asume la doctrina de los indiferentes preferibles, en tanto, a pesar de su indiferencia, es en el uso que hagamos de ellos donde se hará evidente nuestra cualidad moral-epistémica ${ }^{15}$ y donde habremos de encontrar el fin mismo de la reflexión práctica. ${ }^{16}$

Los conceptos de indiferente, preferible $y$ acorde con la naturaleza en Epicteto

Definir cuál es la posición de Epicteto ante la doctrina de los indiferentes no es una tarea sencilla. En principio, la adhesión de Epicteto al núcleo de la posición ortodoxa se hace evidente en la siguiente paráfrasis del pasaje de Estobeo citado anteriormente: "De lo existente, unas cosas son buenas,

${ }^{12}$ D. L., 7, 160; SVF, 1, 351; LS, 58G, traducción de Cappelletti, modificada. “Aristón [...] ubicando todas las cosas, con excepción de virtudes y vicios, en un plano de absoluta igualdad" (Cic., De leg., 1, 38; SVF, 1, 367, traducción de Cappelletti); "Si, como Aristón de Quíos dijo, que sólo es bueno lo que es honesto y malo lo que es deshonesto, y que las demás cosas son todas enteramente iguales y no interesa, en realidad, si están presentes o ausentes" (Cic., De leg., 1, 55; SVF, 1, 367; traducción de Cappelletti). Cf. en general, SVF, 1, 360-367.

${ }^{13}$ Cic., De fin., 3, 15, 50; SVF, 1, 365, traducción de Cappelletti.

${ }^{14}$ Podemos suponer, en efecto, que Aristón opera asimismo un desplazamiento complementario en la definición de sabiduría, volviendo nula la crítica de Cicerón.

${ }^{15}$ Cf. D. L., 7, 104-5; SVF, 3, 104; LS, 58B.

${ }^{16}$ Cf. Stob., Ecl., 2, 76, 9-15; LS, 58K. 
otras malas y otras indiferentes. Buenas son las virtudes y lo que participa de ellas; malas, las maldades y lo que participa de la maldad; indiferente, lo que está entre ambas: la riqueza, la salud, la vida, la muerte, el placer, el dolor". ${ }^{17}$ En un pasaje sobre el que volveremos más tarde, luego de afirmar que si pudiéramos conocer y comprender lo que la providencia nos ha asignado desestimaríamos la distinción entre lo que es acorde con la naturaleza y lo que no lo es, Epicteto concluye: "Pero, en realidad, como no lo

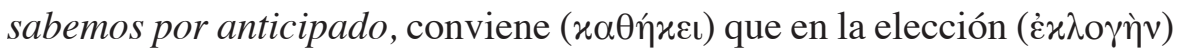
nos atengamos a lo mejor por naturaleza ( $\varepsilon \dot{v} \phi v \varepsilon \sigma \tau \varepsilon \dot{\varrho} \omega \nu$ ह̌ $\chi \varepsilon \sigma \theta \alpha \iota)$, ya que, en efecto, para eso hemos nacido" (2, 10, 4-6).

Hasta aquí, la posición de Epicteto respecto de la doctrina de los indiferentes parece ser ciertamente ortodoxa: dentro de la clase de las cosas indiferentes, existen algunas que naturalmente poseen mayor valor que otras, y es ese valor el que las hace objeto de nuestra elección. Como ha sido frecuentemente notado, no obstante, la distinción entre indiferentes preferibles y dispreferibles se encuentra por completo ausente, en esos términos, de las reflexiones del autor. Ahora bien: ¿expresa esta ausencia el rechazo por parte de Epicteto de toda posible distinción al interior de la esfera de los indiferentes? En caso afirmativo: ¿es esto consecuencia de la influencia de la crítica de Aristón a la doctrina estoica de los indiferentes preferidos? ${ }^{18}$ Si deseamos encontrar una respuesta a estas interrogantes debemos comenzar por analizar una serie de pasajes clave de las Dissertationes:

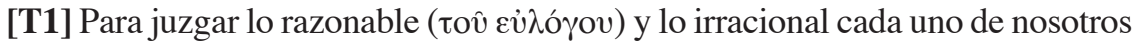

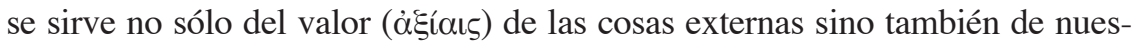

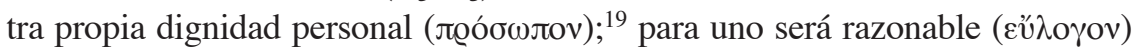
sostener el orinal, teniendo en cuenta simplemente esto: que si no lo sostiene,

${ }^{17}$ Stob., Ecl., 2, 19, 13. Cf. asimismo Epict., Diss., 2, 9, 15 S; 1, 30, 3. En lo sucesivo, cito según la traducción (levemente modificada en algunos casos) de Paloma Ortiz García (Gredos, 1993).

${ }^{18}$ Cabe señalar que el nombre de Aristón no aparece ni en las Dissertationes ni en el Enchiridion. Esto no representa, sin embargo, evidencia alguna en contra de la vinculación entre ambos autores, en virtud no sólo del carácter fragmentario, incompleto e indirecto de los registros de Arriano, sino también del hecho de que las críticas de Aristón pueden haber llegado a Epicteto en forma anónima a través de tratados o de las lecciones de su maestro Musonio Rufo.

${ }^{19}$ Sobre la problemática noción de $\pi \rho$ ó $\sigma \omega \pi$ ov, cf., entre otros, Frede, 2007. 
recibirá golpes y no recibirá comida, mientras que si lo sostiene no padecerá crueldades ni sufrimientos; pero a otro no sólo le parece intolerable el sostenerlo, sino también soportar que otro lo sostenga. Así que si me preguntas: “ ¿He de

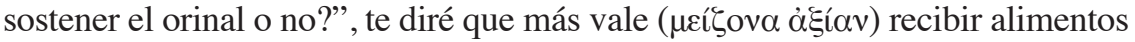
que no recibirlos, y que menos vale ( $\left.\mu \varepsilon^{i} \zeta o v \alpha \alpha^{\prime} \pi \alpha \xi i \alpha v\right)$ recibir golpes que no recibirlos, de modo que si mides tu interés con esos parámetros, ve y sosténselo. “-_Pero eso no sería digno de mí!” Eres tú quien ha de examinarlo, no yo. Eres tú quien te conoces a ti mismo, quien sabes cuánto vales para ti mismo y en cuánto te vendes; cada uno se vende a un precio.

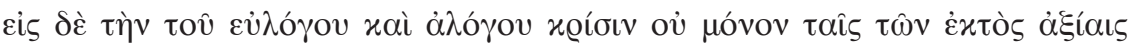

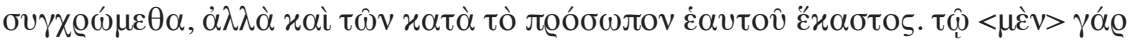

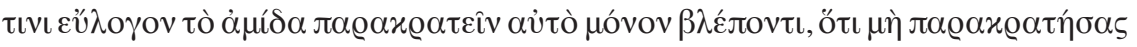

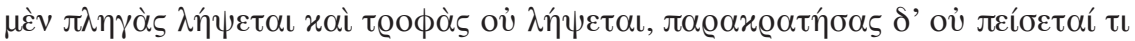

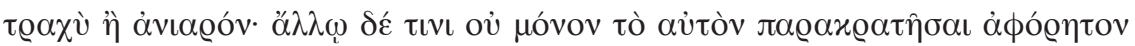

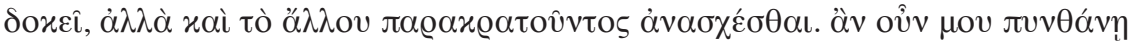

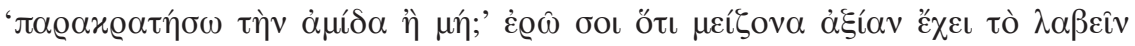

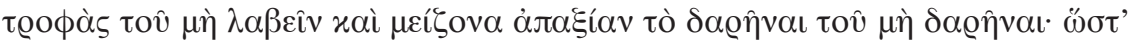

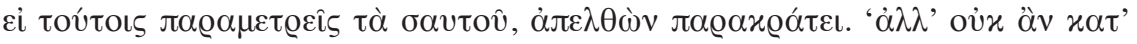

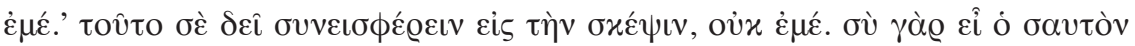

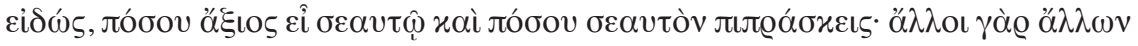

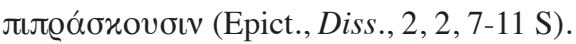

Si nos limitamos a este primer argumento, la posición de Epicteto ante la doctrina de los indiferentes preferidos parece clara: los indiferentes poseen efectivamente un valor ( $\dot{\alpha} \xi i ́ \alpha)$, pero el cálculo del mismo exige incorporar en la ecuación un elemento adicional, a saber, la estimación que cada uno hace de sí mismo y de su propio valor; en otras palabras, a diferencia de la virtud, el valor de las cosas indiferentes es condicional y relativo al sujeto que los evalúa. Esto no implica ciertamente negar

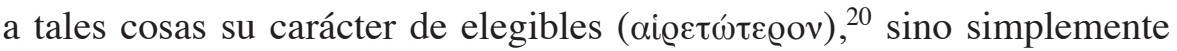
negar que ese carácter sea incondicional, es decir, que posea validez universal. Si esto es así, la posición de Epicteto no parece distar demasiado del primer argumento que encontrábamos asignado por Sexto Empírico a

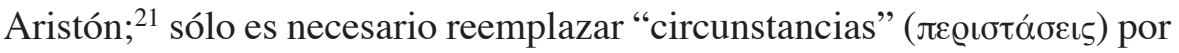

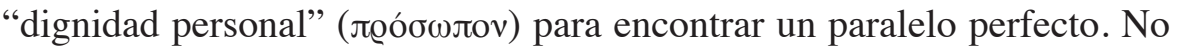

${ }^{20}$ Es precisamente en esos términos que Epicteto plantea el problema en 1, 2, 15: “ ‘Es

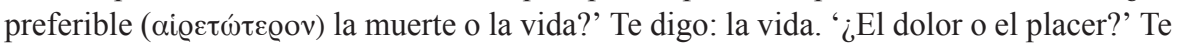
digo: el placer".

${ }^{21}$ Cf. S. E., $M, 2$, 64-7; SVF 1, 361; LS, 58F; citado supra. 
obstante, tres pasajes centrales de las Dissertationes cuestionan la validez de esta conclusión o, cuanto menos, su carácter definitivo:

[T2] ¿Cómo [...] se llama a algunas cosas exteriores acordes con la naturaleza y contrarias a la naturaleza? Como si fuéramos algo aislado (ảjó $\lambda v \tau o \iota)$. Pues en el pie llamaré acorde con la naturaleza a que esté limpio, pero si lo consideras en tanto es un pie y no algo independiente, le corresponderá ( $x \alpha \theta \eta \hat{\xi} \xi \varepsilon$ ) andar por el barro y pisar espinas y a veces hasta ser amputado en beneficio del todo; y si no, no seguirá siendo un pie. Algo así hay que pensar de nosotros. ¿Qué eres? Un ser humano. Si te considera como algo aislado, será acorde con la naturaleza vivir hasta la vejez, ser rico, tener salud. Pero si te ves como hombre y como parte de un todo, te corresponde ( $x \alpha \theta \dot{\eta} x \varepsilon \iota)$ ahora estar enfermo, luego darte a la mar y correr riesgos, luego verte sin recursos y, a veces, hasta morir antes de tiempo. Entonces, ¿porqué te enfadas? ¿No sabes que igual que aquél no seguiría siendo un pie tampoco tú seguirías siendo hombre?

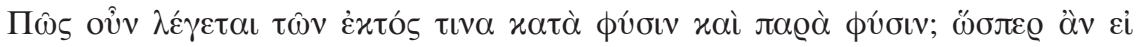

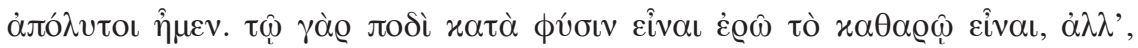

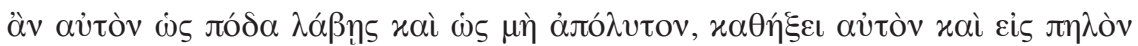

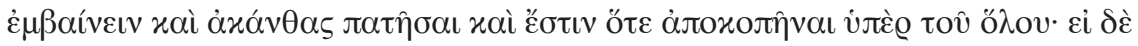

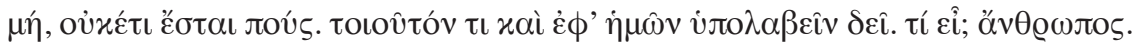

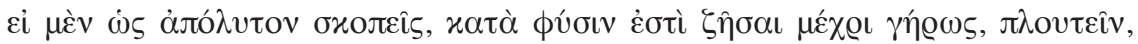

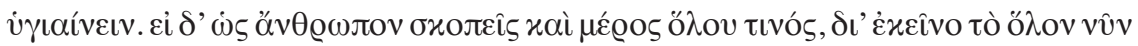

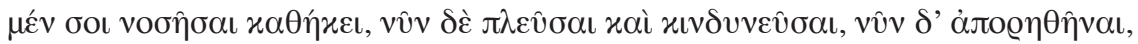

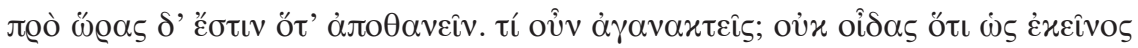

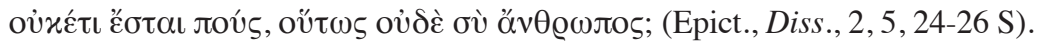

T3 (a) ¿Cuál es la misión del ciudadano? No tener ningún interés personal, no deliberar sobre nada como un ser aislado (àjódvtov), sino del mismo modo que si la mano o el pie tuvieran raciocinio y comprendieran la disposición natural, no tendrían nunca apetencias de otro modo más que con referencia

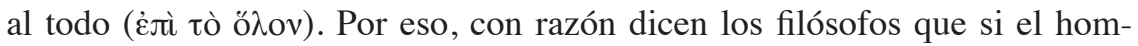
bre bueno y honrado supiera por anticipado lo que va a suceder, colaboraría

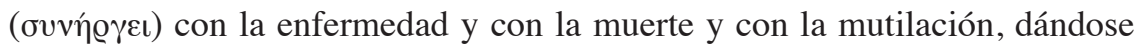
cuenta, sin duda, de que eso se distribuye según la ordenación del todo y de que el todo es superior a la parte y la ciudad al ciudadano. (b) Pero, en realidad, como no lo sabemos por anticipado, conviene ( $x \alpha \theta \dot{\eta} x \varepsilon l)$ que en la

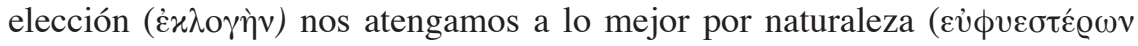

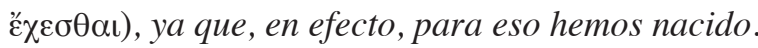

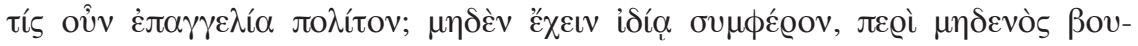

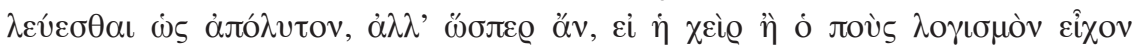




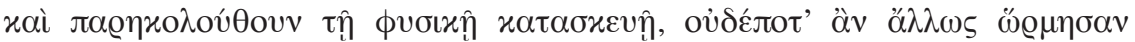

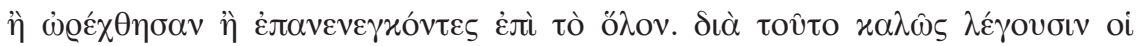

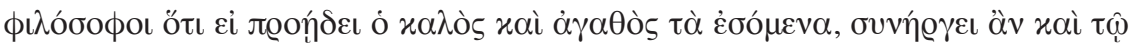

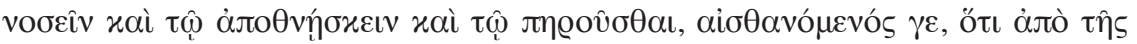

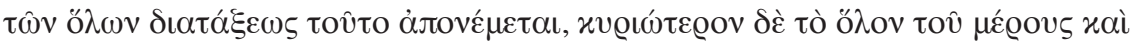

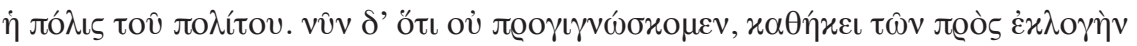

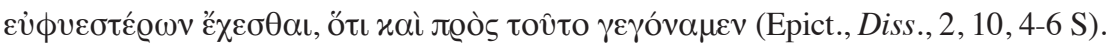

T4 (a) Con razón dice Crisipo: "Mientras me parezcan inciertas las consecuencias siempre sigo lo más adecuado para conseguir lo acorde con la natu-

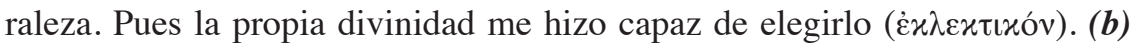
Pero si supiera que ahora es mi destino enfermar, incluso me lanzaría a ello; pues también el pie, si tuviera seso, se lanzaría al barro".

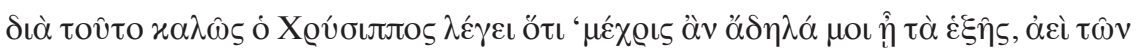

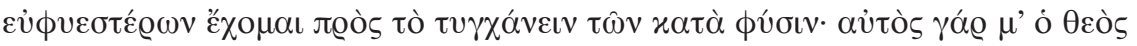

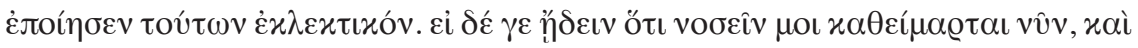

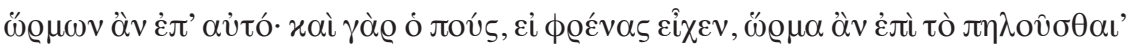
(Epict., Diss., 2, 6, 9-10 S).

Puestos en paralelo, estos tres pasajes expresan a la perfección la indefinición que atraviesa a las reflexiones de Epicteto sobre el problema de los indiferentes. En principio, T2, T3a y T4b permiten reconstruir el siguiente argumento:

a) existen dos perspectivas posibles que se pueden adoptar cuando abordamos el problema del valor de lo externo: la perspectiva de la totalidad y la perspectiva de la finitud;

b) la distinción entre indiferentes acordes con la naturaleza y contrarios a ella sólo tiene sentido si adoptamos la perspectiva de la finitud;

c) no podemos adoptar la perspectiva de la finitud;

d) la distinción entre indiferentes acordes con la naturaleza y contrarios a ella no tiene sentido. ${ }^{22}$

No obstante, T3b y T4a reincorporan la distinción entre indiferentes acordes y contrarios a la naturaleza al admitir la validez de la perspectiva de la finitud. Curiosamente, la reincorporación de esta perspectiva no responde meramente a una necesidad práctica de encontrar una guía para la acción aun a pesar de nuestra finitud (la cual nos impide adoptar la perspectiva

${ }^{22}$ La distinción propuesta por Long (2004, p. 202) entre considerar algo como preferible "in the abstract" e "in practice" se vuelve, en este sentido, innecesaria, dado que la segunda alternativa es simplemente errónea. 
de la totalidad), sino que en ambos pasajes se afirma su carácter absoluto: mientras que T3b la señala como el fin de nuestra vida, T4a representa a la capacidad de elección entre los indiferentes como un regalo de la divinidad.

En síntesis: si atendemos a los pasajes donde Epicteto aborda específicamente el problema de los indiferentes (T1-T4), encontramos tres respuestas divergentes a la pregunta por el valor de los mismos: a) ciertos indiferentes poseen valor [T3b; T4a]; $b$ ) ciertos indiferentes poseen valor, pero ese valor es condicional, relativo $\left.[\mathrm{T} 1]^{23} ; c\right)$ los indiferentes no poseen valor en sí mismos [T2; T3a; T4b]. ${ }^{24}$

Si deseamos encontrar evidencia más sólida e inequívoca, tendremos que considerar la distinción realizada por Epicteto entre aquello que depende de nosotros y aquello que no lo hace. ${ }^{25} \mathrm{El}$ sentido en el que tal distinción (a la que llamaré D) puede contribuir a la comprensión de la posición de Epicteto respecto de la problemática de los indiferentes es claro: allí donde Epicteto permanece en silencio al abordar explícitamente tal problemática, podemos recurrir a $\mathrm{D}$ en busca de razones que inclinen la balanza a uno u otro lado. Si comprendemos cuál es la opinión de Epicteto respecto de cuál es la actitud que deberíamos adoptar ante lo que no depende de nosotros, el problema acerca de si consideraba legítimo y necesario asignar cierto valor a lo indiferente se verá solucionado inmediatamente.

\section{La distinción entre lo que depende de nosotros y lo que no depende de nosotros}

La centralidad que asume en la reflexión ética de Epicteto la distinción entre lo que depende de nosotros y lo que no lo hace [D] no necesita ser

${ }^{23}$ Ésta es la posición que Stephens (2007, pp. 8-9) y Long (2004, p. 84) asignan a Epicteto, y que Long asigna a Aristón en LS, vol. 1, p. 358. Véase, no obstante, la nota siguiente.

${ }^{24}$ Roskam (2005, pp. 112-114) y Long (2004, pp. 201-202) sostienen que es ésta la posición definitiva de Epicteto y que en esto su postura se aleja de la ortodoxia del estoicismo antiguo y se acerca a las críticas de Aristón. Cf. asimismo Sorabji, 2007, p. 93.

${ }^{25}$ Una estrategia alternativa ha sido propuesta por Pierre Hadot, quien afirma que el re-

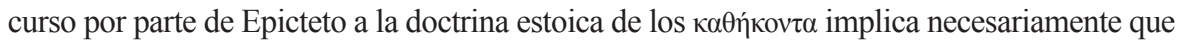
no todo lo exterior al individuo es estrictamente indiferente, y que ello es índice suficiente del distanciamiento de Epicteto respecto de Aristón (cf. Hadot, 1997, p. 87). Como intentaré demostrar, no obstante, la aceptación del concepto de $x \alpha \theta \hat{\eta} \varkappa o v$ no nos obliga a admitir tal conclusión, sino que el rechazo de la doctrina de los indiferentes preferibles puede perfectamente convivir con la idea de que existen ciertas actitudes apropiadas en relación con la exterioridad. 
demostrada. El hecho de que el propio Arriano hubiera decidido emplazar dicha distinción en el inicio tanto de Dissertationes como de Enchiridion es evidencia suficiente del lugar primordial que Epicteto asignaba a la misma en sus lecciones diarias:

Los dioses hicieron que dependiese de nosotros ( $\dot{\varepsilon} \phi ’$ îuî) sólo lo más supremo de todo y lo que dominaba a lo demás: el uso correcto de las representaciones; mientras que lo demás no depende de nosotros. [...] [Zeus:] "Te di una parte de nosotros mismos, la capacidad de impulso y repulsión, de deseo y de rechazo, y, en pocas palabras, la de servirte de las representaciones; si te ocupas de ella y cifras en ella tu bien, nunca hallarás impedimentos ni tropezarás con trabas". [...] Pero en vez de eso, aun pudiendo preocuparnos de un solo objeto y dedicarnos sólo a él, preferimos preocuparnos de muchos y encadenarnos a muchos; al cuerpo, a la hacienda, al hermano, al amigo, al hijo y al esclavo. Así, por estar encadenados a muchos objetos nos vemos oprimidos y arrastrados por ellos. [...] Entonces, ¿qué? Hemos de organizar lo mejor posible lo que no depende de nosotros y servirnos de las demás cosas tal como vienen. ¿Y cómo vienen? Como la divinidad quiere.

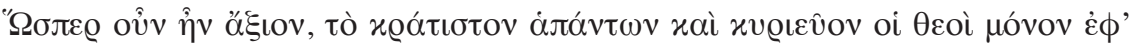

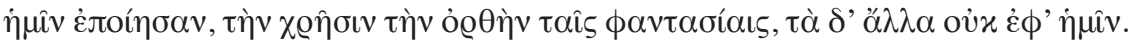

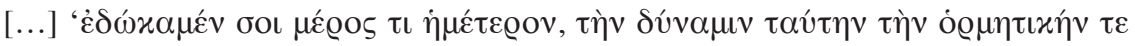

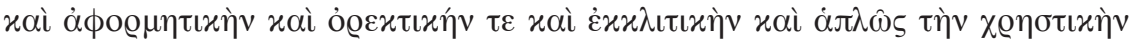

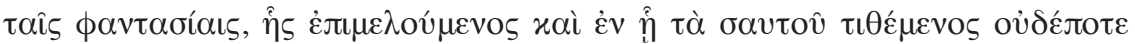

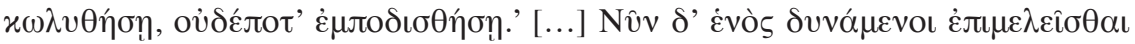

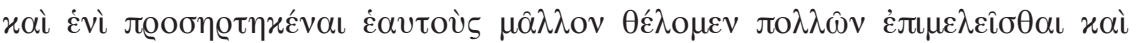

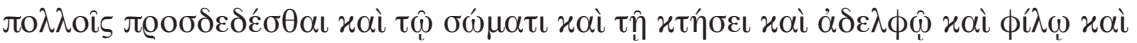

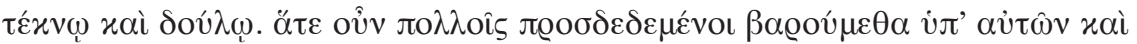

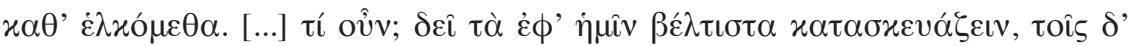

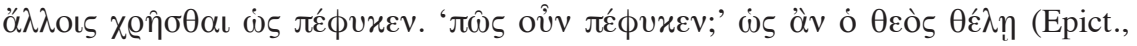
Diss., 1, 7-17 S).

Ciertas cosas dependen de nosotros y otras no dependen de nosotros. Dependen de nosotros nuestras opiniones, impulsos, deseos y rechazos, y, en una palabra, todas nuestras acciones. No dependen de nosotros nuestro cuerpo, las riquezas, la reputación, el poder, y, en una palabra, todo lo que no son nuestras acciones.

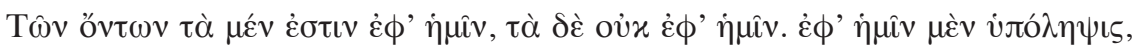

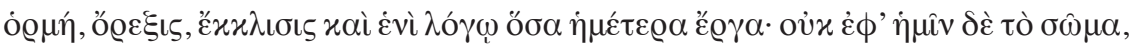

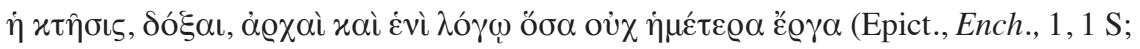
la traducción es mía). 
La distinción entre lo que depende y lo que no depende de nosotros [D] (que ya he analizado en otras ocasiones ${ }^{26}$ y que me limito aquí a resumir en pocas líneas) puede ser abordada desde dos perspectivas parcialmente complementarias: la primera de ellas consiste en enmarcarla en la problemática estoica del determinismo y el compatibilismo (i. e., la pregunta acerca de si los estoicos consideraban que los conceptos de libertad y de responsabilidad moral poseen sentido dentro de un horizonte estrictamente determinista). Si bien esta problemática ha atraído la atención de numerosos comentaristas ${ }^{27}$ a lo largo del último siglo en lo que respecta al estoicismo antiguo, el hecho de que la bibliografía al respecto sea (comparativamente) escasa en el caso específico de Epicteto ${ }^{28}$ se debe a que las Dissertationes no ofrecen (como sucede allí con muchos otros aspectos de la doctrina estoica) un abordaje explícito y sistemático de la problemática del determinismo.

Cabe destacar, no obstante, que, aun cuando existe un consenso extendido en cuanto a que la ausencia de un tratamiento explícito por parte de Epicteto de la problemática del determinismo no nos obliga a suponer que se haya desentendido de dicha problemática, dos puntos claves permanecen en el centro de la discusión: el primero de ellos tiene que ver con el lugar que debemos otorgar a la radicalidad de la distinción entre lo que depende y lo que no depende de nosotros en relación a la problemática del determinismo, es decir, si debemos o no suponer que la insistencia por parte de Epicteto sobre el hecho de que nuestro asentimiento depende de nosotros (o está en nuestro poder) debe ser interpretado como índice de la presencia de un momento de indeterminación en la psicología de la acción humana y, en consecuencia, como expresión de un distanciamiento doctrinal respecto de la ortodoxia estoica. ${ }^{29} \mathrm{El}$ segundo elemento que ha

${ }^{26}$ Vid. Braicovich, 2008b, 2010, 2011 y 2012.

${ }^{27}$ Dado que la bibliografía sobre esta problemática se ha vuelto inabarcable en las últimas décadas, remito al lector a las bibliografías de Bobzien, 1998, y Salles, 2006, los cuales representan los dos estudios de conjunto recientes más sistemáticos sobre el tema en cuestión.

${ }^{28}$ Cf. especialmente Bobzien, 1998, pp. 330-337; Salles, 2005, pp. 62-63, 91-110; Dragona-Monachou, 2007; Long, 2004, pp. 210-230; Hahm, 1992; Dobbin, 1991; Gourinat, 2005; Eliasson, 2008, pp. 109-14; Hadot, 1997, pp. 99-101.

${ }^{29}$ Cf. a este respecto Dobbin, 1991; Bobzien, 1998b, pp. 335-6; Long, 2004, pp. 229-230; Gourinat, 2005, p. 124; Salles, 2005, p. 63 n. 36; Eliasson, 2008, p. 114. A pesar de que la posición defendida por Dobbin (1991) ha sido la que ha estado en el centro de la discusión, la misma debe ser matizada con la interpretación del problema del determinismo epistémico ofrecida posteriormente por el propio Dobbin (2008) en su edición comentada de Epicteto. 
sido objeto de discusión consiste en la pregunta acerca de hasta qué punto la problemática específica de la atribución de responsabilidad moral opera como un disparador de las reflexiones de Epicteto sobre el problema del determinismo, es decir, si Epicteto permanece, como lo resume Eliasson (2008, pp. 109-114), en el horizonte definido al inicio del libro III de la Ethica nicomachea o si, por el contrario, su análisis de D debe ser interpretado en un contexto fundamentalmente terapéutico (vinculado con el

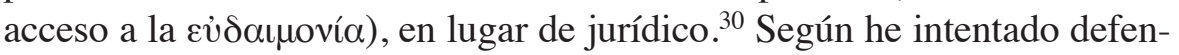
der en otras ocasiones, el hecho de que existan ciertas cosas que dependen de nosotros no implica en absoluto suponer que el accionar de nuestra

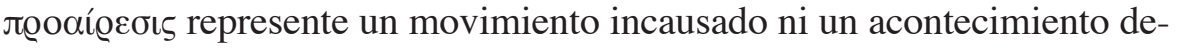
terminado por un "yo" trascendente al estado epistémico del alma de un individuo en determinado momento; muy por el contrario: los elementos textuales de las Dissertationes. que se vinculan efectivamente con esta problemática sugieren que Epicteto desarrolla una de las versiones más radicales e intransigentes de la una psicología y una ética deterministas que encontramos en la historia de la filosofía antigua. ${ }^{31}$

La segunda perspectiva (complementaria de la anterior) desde la cual puede ser abordada la distinción entre lo que depende y lo que no depende de nosotros [D] consiste en el hecho de que, como ha sido señalado por Susanne Bobzien, ${ }^{32}$ dicha distinción supone una restricción fundamental, en comparación con el tratamiento de dicho concepto ( $\dot{\varepsilon} \pi \dot{\imath}+$ dativo) en Crisipo, respecto de aquello que efectivamente depende de nosotros. Esta restricción responde a la convicción de Epicteto acerca de la imposibi-

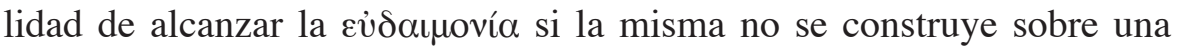
base absolutamente inconmovible por los golpes de la fortuna. Desde esta perspectiva, la búsqueda emprendida por Epicteto es de algo que no pueda, por definición, ser quitado de nuestras manos, de algo cuya posesión y dominio no pueda, de manera alguna, ser amenazado por otros. Esto implica hasta cierto punto, una redefinición sustancial de lo que entendemos por acción humana, en la medida en que Epicteto sólo admite dentro de esta categoría acontecimientos mentales de tipo (directa o indirectamente) cognitivo (asentimientos, opiniones, deseos, etc.), y excluye no sólo los

${ }^{30} \mathrm{Cf}$. a este respecto véase fundamentalmente Bobzien, 1998b, pp. 337-8 y Salles, 2005, pp. 91-110.

${ }^{31}$ Remito para una defensa de esta posición a las referencias citadas en la nota 26.

${ }^{32}$ Cf. Bobzien, 1998b, pp. 331-3. 
efectos de nuestras acciones sobre la exterioridad sino también los movimientos corporales que traducen (o intentan traducir) nuestros impulsos (ọ́ú) en acciones exteriormente observables. ${ }^{33}$

Como se hace evidente, no obstante, y partiendo de esta última perspectiva, D debe ser complementada con la especificación adicional de que lo que sí depende de nosotros admite dos calificaciones opuestas: bueno-malo, correcto-incorrecto, virtuoso-vicioso. Podemos sostener opiniones verdaderas o erróneas; experimentar deseos racionales o irracionales; hacer un uso correcto o incorrecto de nuestras impresiones; podemos, en suma, ex-

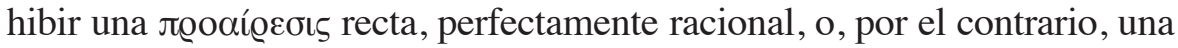
pervertida, irracional, ciega. Una vez establecida esta precisión adicional, se hace evidente que el rango de los elementos que caen bajo cada una de las alternativas de esta tripartición coincide a la perfección con la doctrina de los indiferentes desarrollada por el estoicismo antiguo. ${ }^{34}$ No obstante, la identificación directa entre las nociones de lo indiferente y aquello que no depende de nosotros no procede de la mera coincidencia en el rango de objetos designados por cada una de ellas. El vínculo lógico que fundamenta tal identificación se funda en el siguiente argumento: a) Existe una clase de cosas que pueden ser obstaculizadas o, mejor, respecto de las cuales nosotros podemos ser obstaculizados en el intento de obtenerlas o conservarlas. b) Aquellas cosas respecto de cuya obtención o conservación podemos ser obstaculizados no dependen de nosotros. c) Nuestra felicidad no se puede construir sobre, ni puede ser amenazada por, cosas que pueden ser obstaculizadas (i. e., que no dependen de nosotros). d) Aquellas cosas que pueden ser obstaculizadas (i. e., que no dependen de nosotros) son indiferentes en relación con nuestra felicidad. Este argumento se apoya en el primero de los principios que, como señalábamos al inicio de este trabajo, encontramos en las fuentes del estoicismo antiguo en relación al concepto de lo indiferente, a saber, la idea de que lo indiferente es tal en tanto no es condición ni suficiente ni necesaria de la virtud. ${ }^{35}$ Podemos, en consecuencia, llevar una

${ }^{33}$ Cf. Epict.,Diss. 2, 16, 15 y 4, 1, 68-75.

${ }^{34}$ Ciertamente, los cambios introducidos por Epicteto al definir lo bueno/virtuoso no

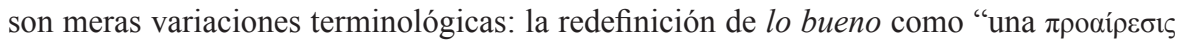
correcta" o como el "uso correcto de las impresiones" resume precisamente el núcleo de las reflexiones más innovadoras de Epicteto respecto del legado estoico.

${ }^{35}$ El tercer principio que mencionábamos allí, es decir, que lo indiferente es tal porque puede ser usado tanto virtuosa como viciosamente, aparece en una sola ocasión en Dissertationes y no asume ningún papel estructural en las argumentaciones de Epicteto. 
buena vida (i. e., una vida virtuosa, acorde con la naturaleza) aun en una situación de absoluta pobreza, escarnio público y enfermedad. D se vuelve decisiva, de esta forma, en virtud de que una comprensión adecuada de las verdaderas dimensiones de tal distinción conduce necesariamente a una resignificación de la totalidad de las relaciones que establecemos con aquello que nos rodea, aquello que es exterior a nosotros y que es independiente de nuestros deseos. La comprensión del hecho de que la gloria y la riqueza no dependen de nosotros, de que no tienen nada que ver con nosotros en un sentido esencial, de que son extrañas y ajenas a nosotros, debería conducirnos en forma automática a liberarnos de las perturbaciones que alteran la serenidad de nuestra vida mental y que nos alejan del estado ideal que deberíamos alcanzar, a saber, la ev̌ooı $\alpha$, el buen fluir de la vida. ${ }^{36}$

Ahora bien: ¿cuál es la actitud precisa que deberíamos exhibir idealmente ante aquello que no depende de nosotros, ya sea que se trate del destino de alguno de nuestros familiares, de nuestras riquezas o de nuestra salud? (Si bien la pregunta puede parecer ociosa, en tanto el reconocimiento de la indiferencia de algo parece exigir lógicamente una actitud de indiferencia ante ello, debemos notar que ése es precisamente el problema que introduce la idea de los indiferentes preferibles, a saber, que nos obliga a admitir que la indiferencia no es la actitud adecuada ante los indiferentes o, en otras palabras, que los indiferentes no deben "sernos indiferentes".) En términos generales, podemos suponer tres tipos básicos de actitudes que se pueden asumir frente a lo exterior: rechazo, indiferencia o aprobación. Es claro que esta última alternativa no constituye una opción aceptable para el estoicismo. Menos aún lo es para Epicteto: si bien su carácter de indiferente debería ser suficiente para desestimar una actitud positiva (afecto, amor, apego, etc.) hacia lo exterior, el filósofo posee una razón adicional para rechazar tales actitudes, a saber, la convicción de que todo vínculo de afecto con la exterioridad equivale lisa y llanamente a la esclavitud: "Te inclines a donde te inclines, te haces esclavo, te subordinas, te sometes a impedimentos, a

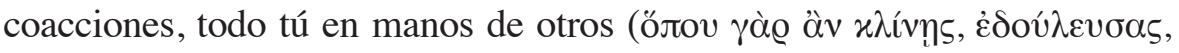

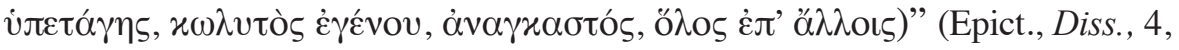
4, 33-34). ${ }^{37}$ William Stephens ha percibido la absoluta centralidad de esta problemática al calificar a la creencia de que lo exterior no es indiferente

\footnotetext{
${ }^{36}$ El simple reconocimiento de que lo que no depende de nosotros no puede garantizarnos la felicidad ni ponerla en riesgo es suficiente por sí mismo para alcanzar la misma.

${ }^{37} \mathrm{Cf}$. asimismo Epict., Diss. 4,1,77.
} 
como una "creencia subhumana": 38 en efecto, el error de estimar, apreciar o adorar lo externo es para Epicteto suficiente para considerar a aquel que exhibe tal actitud como un individuo cuya defectuosa racionalidad lo pone más cerca de las bestias salvajes que de los hombres racionales. ${ }^{39}$ Idénticas consideraciones valen, por otra parte, para la alternativa opuesta: el rechazo, el desprecio o el odio constituyen actitudes tan ilegítimas como la fascinación y el apego excesivo. Nuevamente, las razones de Epicteto son dos: sumado al hecho de que sólo tendríamos razones para despreciar algo si consideráramos que está dotado de cierta cualidad negativa que se

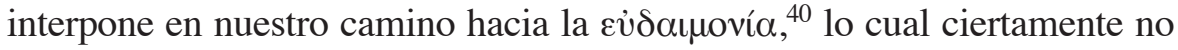
es el caso tratándose de indiferentes, Epicteto insiste adicionalmente sobre el hecho de que el desprecio activo de lo exterior puede transformarse en motivo de perturbaciones e inquietudes. ${ }^{41}$

¿Deberíamos optar entonces por la desidia, por un rousseauniano desinterés hacia aquello que nos rodea, sean piedras, vecinos o amigos? ¿Deberíamos simplemente hacerlos a un lado, excluirlos de nuestras consideraciones y de los proyectos que dan forma a nuestra praxis cotidiana en el mundo? Esa parece ser, efectivamente, la alternativa a la que nos exhorta Epicteto en numerosos pasajes de las Dissertationes al recomendar que nos apartemos de lo externo $(1,3,18 ; 3,3,14-16 ; 4,1,110 ; 4,4,39 ; 4$, $6,9 ; 4,7,35)$ y al señalar que no nos concierne en nada $(1,25,1 ; 1,30$, $3 ; 2,1,6 ; 3,3,14-16)$ y que es ajeno y extraño a nosotros $(1,25,1 ; 2,16$, $27 ; 4,1,81 ; 4,6,9)$. Tales pasajes parecen conducir en forma decisiva a una política de desinterés absoluto por todo aquello que no depende de nosotros, por todo aquello que es exterior a nosotros y que nada tiene que ver con nosotros, ya sea que se trate de un pedazo de papel o un hijo, una planta o la persona a la que creo amar. ${ }^{42}$

${ }^{38}$ Cf. Stephens, 2007, p. 32.

${ }^{39}$ Cf. Epict., Diss., 2, 22, 26.

${ }^{40} \mathrm{Si}$ bien Epicteto comete por momentos el error lógico de referirse a ciertos indiferentes (en particular a las posesiones materiales) como algo que debe ser despreciado, considero que esto no es más que una exageración con fines persuasivos; cf. Epict., Diss., 3, 24, 12 , 56. Como señala Stephens (2007, p. 73), es precisamente la negativa a adoptar una actitud de activo rechazo de lo exterior lo que distingue al estoico del cínico.

${ }^{41}$ Cf. especialmente Epict., Diss., 4, 4.

${ }^{42}$ Cf. Epict., Diss., 1, 2, 21; 1, 12, 18-20; Epict. Ench., 11, 15. ¿Podemos reducir la tendencia a considerar lo exterior como indiferente, como obstáculo, como algo de lo que hay que deshacerse, como expresión de la herencia cínica del pensamiento de Epicteto? 


\section{Doctrinas y pasajes problemáticos}

La imagen que se desprende del párrafo anterior no se corresponde, ciertamente, con la concepción de la importancia del otro que se desprende de pasajes como el siguiente:

¿Qué quieres estar haciendo cuando te halle la muerte? Yo, por mi parte: alguna obra humana, benéfica, útil para la comunidad, noble. Si no puedo ser hallado haciendo cosas tan grandes, por lo menos algo sin trabas, lo que se me ha dado, corrigiéndome a mí mismo, perfeccionando mi capacidad de uso de las representaciones, ejercitando la impasibilidad, rindiendo lo propio de mi condición natural.

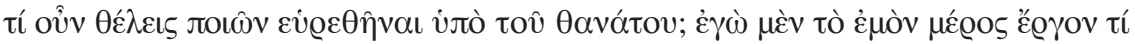

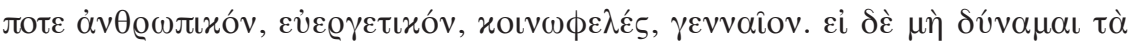

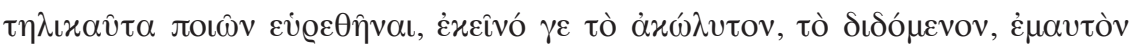

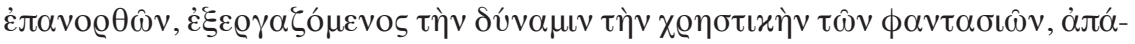

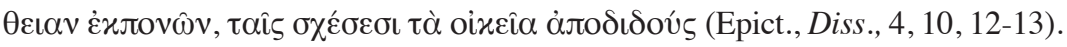

Más aun: el constante recurso de Epicteto a la idea de que existen ciertos roles sociales que debemos cumplir acabadamente, ${ }^{43}$ su insistencia en la necesidad de no descuidar nuestras relaciones con la exterioridad y las reiteradas críticas a las consecuencias antisociales que se desprenden de las doctrinas de Epicuro (así como a la contradicción performativa en la que Epicuro incurre al redactar tratados de ética ${ }^{44}$ ), parecen sugerir que - contrariamente a lo señalado anteriormente - el propio Epicteto no creía que la indiferencia ante lo que no depende de nosotros fuera la única actitud legítima posible. Si así lo fuera, ¿porqué habría de insistir Epicteto en advertirnos que el carácter indiferente de lo exterior no debe ser motivo para que caigamos en la negligencia y el descuido ${ }^{45}$

Creo que no: tanto las reflexiones éticas del cinismo como las del estoicismo se articulan alrededor del principio de la indiferencia de lo externo, y creo que la diferencia entre ambas escuelas en este respecto es fundamentalmente de matices, de énfasis. En cualquier caso, es evidente que un estoico no necesita de ninguna influencia cínica para considerar lo exterior como indiferente: su propia doctrina le exige hacerlo.

${ }^{43}$ Cf. Epict., Diss., 1, 2, 19; 2, 9; 2, 10, 7; 2, 14, 8; 2, 17, 31; 3, 1, 25; 3, 2, 3; 3, 3, $6 ; 3,7,25 ; 3,18,5 ; 3,23,3 ; 3,24,46 ; 4,1,122,159 ; 4,5,10 ; 4,6,26 ; 4,8,20 ; 4$, 12, 16; Epict., Ench., 24, 4, 30 S. Vid. Frede, 2007.

\footnotetext{
${ }^{44}$ Cf. Epict., Diss., 1, 23; 3, 7, $19 \mathrm{~S}$.

${ }^{45}$ Cf. especialmente Epict., Diss., 2, 5; 1, 29, 1; 2, 6, 1-3 S.
} 
Creo que la totalidad de estos pasajes pueden ser explicados sin necesidad de suponer que Epicteto otorga a lo exterior/indiferente ningún tipo de valor, no al menos el tipo de valor necesario para transformar a un indiferente en preferible en comparación con otro. La exigencia de no descuidar las relaciones que establecemos con la exterioridad y de desempeñar correctamente los roles y funciones que tales relaciones necesariamente nos imponen debe ser comprendida en el marco definido por un argumento de tipo teleológico que recorre la totalidad de la obra de Epicteto, a saber: $a$ ) toda especie posee una naturaleza propia; $b$ ) todo individuo debería actuar de acuerdo a la naturaleza de su especie; c) la naturaleza de los hombres es ser racionales y sociales (i.e., fieles, leales, respetuosos, nobles, serviciales); por lo tanto, $d$ ) todo hombre debería actuar de forma racional y social (i. e, fielmente, lealmente, etc.). ${ }^{46}$ En relación con este argumento, la exigencia de acatar las obligaciones impuestas por nuestras relaciones sociales y familiares no implica en absoluto que aquel que se encuentra del otro lado de la relación posea valor alguno ni que deba ser considerado como un fin en sí mismo. ${ }^{47}$ En pocas palabras, el otro es un medio, reemplazable y carente de valor en sí mismo; y el único valor que Epicteto le reconoce es puramente instrumental. ${ }^{48}$ (Los polos de la relación moral, en este sentido, no somos el "otro" y "yo", sino "yo" y mi conciencia o - en caso de adoptar una interpretación personalista de la teología de Epicteto- Zeus y yo). El desempeño que Epicteto nos exige de nuestros roles puede ser así satisfecho en un modo cuasi mecánico, automático, sin necesidad de establecer un compromiso de tipo afectivo

${ }^{46}$ Cf. Epict., Diss. 2, 4, 1; 2, 9; 2, 10; 3, 1, 25; 3, 23, 3 S.

${ }^{47}$ Más aun, cabe suponer lo contrario: cuanto menos virtuoso sea aquél con quien me relaciono y más difícil se torne la relación, más habrá de contribuir a mi progreso moral, en tanto me permitirá ejercitar virtudes como la paciencia, la tolerancia, etc. Cf., entre otros, Epict., Diss., 3, 20 S.

${ }^{48}$ Cf. Epict., Diss. 1, 19, 11; 2, 3, 7-10; 3, 18, 5; 4, 11; Epict., Ench., 30 S. Vid. Rist, 1978, p. 265; Stephens, 2007, p. 86; Long, 2004, p. 237. Cabe advertir que estas conclusiones deben ser consideradas contra el trasfondo providencialista del estoicismo en general: no hay necesidad de preocuparse por el otro porque lo que sea que la providencia le haya asignado es un hecho positivo que contribuye a la racionalidad y armonía del cosmos. Complementariamente, si el otro no puede comprender el carácter positivo y racional de todo aquello que le acontece, al menos la naturaleza/Zeus lo ha provisto de los recursos necesarios para soportarlo y para ser feliz sin importar lo que ocurra. Cf. Epict., Diss., 1, 6, 26-43; 1, 12, 30; 1, 29, 39; 3, 10; 3, 24, 1-3. 
con el otro, y esto es suficiente para evitar las consecuencias antisociales de una filosofía como la de Epicuro. ${ }^{49}$

¿Es posible explicar la exigencia de no ser descuidados respecto de aquello que no depende de nosotros apelando a razones similares a éstas? Creo que sí. En principio, dicha exigencia aparece fundamentalmente como consecuencia de la preocupación de Epicteto por las consecuencias antisociales que (correctamente) intuye que se derivarían de su insistencia en la idea de que lo que no depende de nosotros es ajeno a nosotros, no nos concierne en nada, etc. Pero esto no significa, nuevamente, que ese cuidado implique una preocupación por el destino de los otros ni un compromiso de tipo afectivo con ellos. Esto por dos razones: la primera, porque tal tipo de vínculos es precisamente el que puede conducirnos a perturbaciones y alejarnos de la

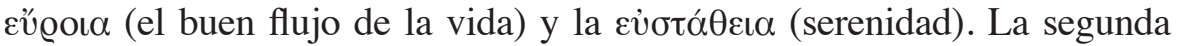
razón es algo más compleja y exige detenernos por un momento en el pasaje 2, 5, 1-8 de las Dissertationes, que es donde encontramos expuesta con mayor fuerza la advertencia en contra del descuido:

Las materias son indiferentes, pero el uso de ellas no es indiferente. ¿Cómo conservaré al mismo tiempo el equilibrio y la imperturbabilidad y a la vez el cui-

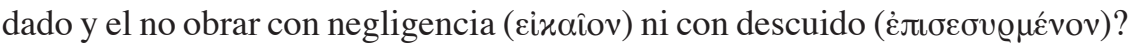
Imitando a los que juegan a los dados: las fichas son indiferentes, los dados son indiferentes. ¿Cómo sé qué va a salir? Pero usar cuidadosa y hábilmente lo

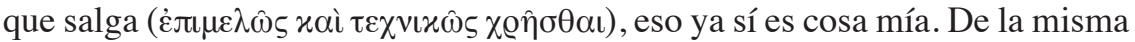
manera, por tanto, en eso consiste la tarea principal de la vida. Distingue las cosas y ponlas por separado y di: «Lo exterior no depende de mí, la proairesis depende de mí. ¿Dónde buscaré el bien y el mal? En lo interior, en mis cosas. Pero no califiques nunca las cosas ajenas de bien ni de mal, ni de provecho ni de perjuicio ni de ningún otro nombre de ese estilo. Entonces, ¿qué? ¿Han de ser usadas esas cosas descuidadamente? De ningún modo, pues eso, a su vez, es un mal para la proairesis y, en ese sentido, contra naturaleza. Sino que hay que hacerlo al mismo tiempo con interés, porque su uso no es indiferente, y a la vez con equilibrio y serenidad, porque la materia es indiferente. Pues donde esté lo importante, en eso nadie puede ponerme impedimentos ni obligarme. En donde se me pueden poner impedimentos o se me puede forzar, la obtención de esas cosas no depende de mí, ni es un bien o un mal; su uso, por otro lado, es o un bien o un mal y, además, depende de mí.

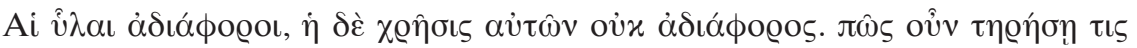

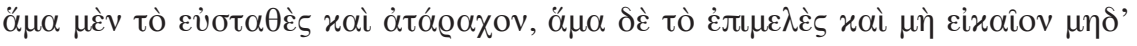

${ }^{49}$ Vid. a este respecto, Braicovich, 2012b y 2012 c. 


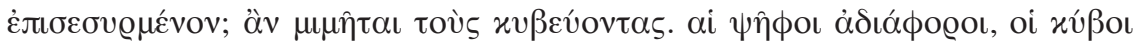

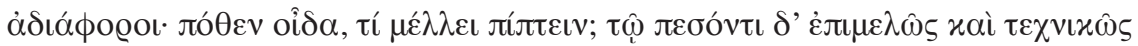

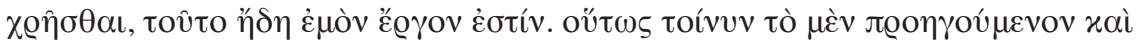

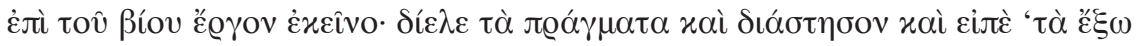

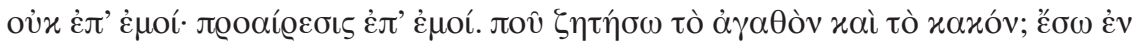

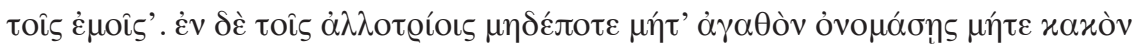

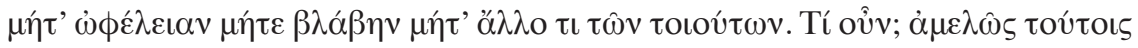

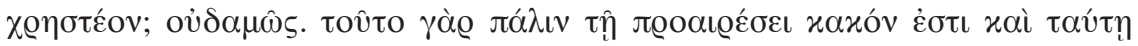

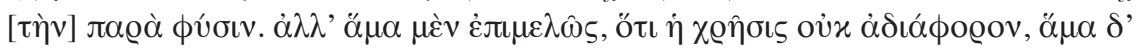

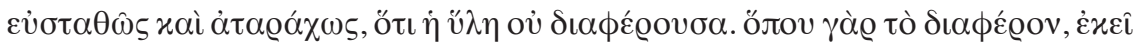

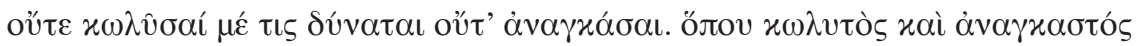

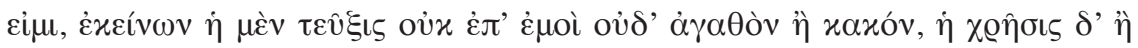

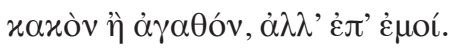

Al menos dos interrogantes surgen ante la lectura de este pasaje: ¿en qué consiste esa preocupación por lo indiferente que nos demanda Epicteto? ¿No es esta preocupación o cuidado en el uso de los indiferentes una reins-

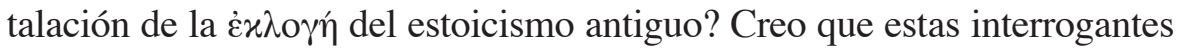
se resuelven si nos detenemos a considerar cuál es el objeto de esta preocupación. A lo largo de 2, 5, Epicteto recurre a dos célebres analogías para distinguir lo indiferente en sí mismo respecto del uso de lo indiferente: un juego de dados y un juego de pelota. En ambos casos, lo indiferente está representado por los materiales utilizados para jugar (dados, pelota), mientras que lo que no es indiferente es, en el primer caso, el uso que hacemos de los números que han arrojado los dados y, en el segundo, el juego en sí mismo, i. e, la manera de jugar (la destreza, rapidez, etc.). Atendiendo a ambas analogías, el terreno de lo indiferente parece asumir una importancia decisiva, en tanto se vuelve el material respecto del cual debemos tomar decisiones que se vinculan, en el fondo, con nuestra cualidad moral y epistémica. Esta conclusión, sin embargo, es falsa, y probablemente la ambigüedad del pasaje se deba en parte a la inadecuación de estas dos analogías, que procede del hecho de que ambas parecerían sugerir que hay alternativas reales y sustantivas en el uso de lo indiferente, cuando la realidad es que no las hay, sino que la única alternativa legítima es la indiferencia. En otras palabras,

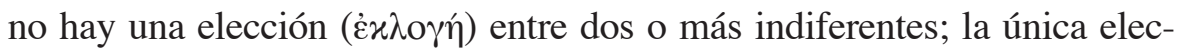
ción ${ }^{50}$ posible es entre permitir que los indiferentes se vuelvan un motivo de

${ }^{50}$ En rigor, dada la base cognitivista del estoicismo de Epicteto, no se trata en este caso de una elección, sino simplemente de haber asentido con firmeza a la impresión/pro- 
preocupación (lo cual implica no comprender su carácter de indiferentes) o no. ${ }^{51}$ En suma: en ningún momento 2, 5 sugiere que lo indiferente (los dados, la pelota; lo cual en el caso ejemplar de Sócrates equivale a la prisión, el exilio, la posibilidad de dejar a sus hijos huérfanos, etc.) debería ser el objeto de nuestra preocupación, no al menos como un fin en sí mismo; el único "uso" posible que podemos hacer de lo indiferente es adoptar una actitud correcta o incorrecta respecto de ellos, y es esta actitud por la que deberíamos preocuparnos y cuidar. ${ }^{52} \mathrm{Si}$ sumamos a esta conclusión el hecho de que la primera mitad de 2, 5 (que es donde encontramos la discusión anterior) es presentada por el propio Epicteto como fundamento para la negación de la distinción entre indiferentes acordes con la naturaleza y contrarios a ella (T2), se hace evidente que la exigencia de Epicteto de no descuidar lo indiferente no puede ser utilizada (como hace Long) en apoyo a la idea de que aquél habría defendido la asignación condicional de valor/disvalor a la totalidad de los indiferentes..$^{53}$

Cabe mencionar, antes de finalizar, una doctrina que fue objeto de una interesante discusión en la última década y que parecería, a primera vista, exigir ciertos matices respecto de la idea de que la indiferencia es la única actitud legítima ante lo indiferente. La doctrina en cuestión está representada por la idea de que el hecho de que los objetos y acontecimientos exteriores sean en sí mismos indiferentes no nos condena a una actitudad de indiferencia ante los mismos, en la medida en que podemos abrirnos a la exterioridad siempre y cuando nuestros impulsos se vean acompañados por

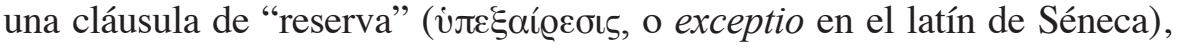
i. e., siempre y cuando tengamos presente que nuestros impulsos pueden verse frustrados por circunstancias que no dependen de nosotros. ${ }^{54} \mathrm{La}$ ven-

posición que afirma que lo que no depende de nosotros es indiferente; se trata, en última instancia, de una operación puramente intelectual.

${ }^{51}$ Tal conclusión se hace evidente en la tercera de las analogías utilizadas por Epicteto en 2, 5, a saber, a la del capitán de un barco que enfrenta una tormenta.

${ }^{52}$ Cabe recordar, en este sentido, que el acto de aprehender la distinción entre lo que depende y lo que no depende de nosotros no sólo es calificado por Epicteto como la "tarea principal de la vida" $(2,5,4)$, sino también como el objetivo último de la educación (1, $22,9)$.

${ }^{53}$ Cf. Long, 2004, p. 184.

${ }^{54}$ En rigor, el marco doctrinal que enmarca la doctrina del "impulso con reservas" es el del ordenamiento providencial del cosmos, y tienen por objetivo garantizar la adecuación de nuestros deseos al devenir efectivo de la realidad, lo cual representa una condición 
taja fundamental del recurso a esta doctrina consiste en que parece ofrecer una posible salida a la clausura operada por Epicteto al emplazar como doctrina central y articuladora la distinción entre lo que depende y lo que no depende de nosotros (y al construir sobre ella el camino hacia la virtud y la $\varepsilon \dot{v} \delta \alpha \iota \mu \nu i^{\alpha} \alpha$ ). Si bien esta doctrina (presente asimismo en Séneca y Marco Aurelio) aparece en forma explícita en sólo dos ocasiones, ${ }^{55}$ encontramos en las Dissertationes y en el Enchiridion una serie importante de pasajes que abordan este mismo problema a través de una estrategia análoga ${ }^{56}$ a saber, la idea de que deberíamos gozar de las posesiones presentes recordándonos a nosotros mismos a cada momento que se trata de bienes efímeros, que no dependen de nosotros y que, en consecuencia, podemos perderlos al instante siguiente. ${ }^{57}$ La rememoración constante de esta cláusula de la fugacidad, como podríamos llamarla, debería lograr que evitemos desarrollar actitudes irracionales como la fascinación o el apego excesivo, actitudes que habrán de conducirnos eventualmente a la frustración ${ }^{58}$ y debería prepararnos para que ningún acontecimiento externo nos tome por sopresa:

Cuando beses a un hijito tuyo o a un hermano o a un amigo, nunca dejes ir del todo tu fantasía ni permitas que tu efusión vaya hasta donde ella quiera, sino tira de ella, conténla, como los que están en pie a espaldas de los que celebran el triunfo y les recuerdan que son humanos. Tú también recuérdate a ti mismo algo así: que amas a un mortal, que no amas nada de lo tuyo; te ha sido dado para este momento, no como cosa inalienable ni para siempre, sino igual que un higo o un racimo de uva de determinada estación del año [...] Y, por lo demás, en el momento en que disfrutes con algo, propónte las impresiones contrarias. ¿Qué mal hay en que, mientras besas a tu hijo, digas susurrando "mañana morirás"? Y lo mismo con el amigo, "mañana te marcharás, o tú o yo, y ya no nos veremos".

necesaria para que nuestros deseos no se vean frustrados y podamos, en consecuencia,

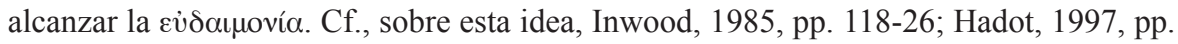
209-16; Brennan, 2000; Brunschwig, 2005; Brennan, 2005, pp.107-10.

${ }^{55}$ Cf. Epict., Ench., 2 S y M. Ant. [Medit.], 11, 37.

${ }^{56}$ Cf. Epict., Diss. 3, 24, 59-67; 3, 24, 85-88; 4, 1, 159; Ench. 3; 21; 26.

${ }^{57}$ Vid. Braicovich, 2012b y 2012 c.

${ }^{58}$ En rigor, el rechazo por parte de Epicteto de este tipo de actitudes no se funda en el hecho de que necesariamente habremos de perder tales posesiones o de que el objeto de nuestro afecto desaparecerá. Esto no es más que una eventualidad que puede o no tener lugar. Lo decisivo es que se trata de cosas que podemos llegar a perder, y la sola consideración de tal posibilidad puede ser causa de nuestra miseria. 


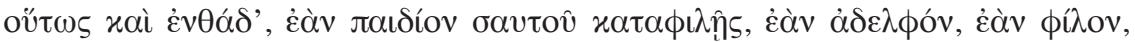

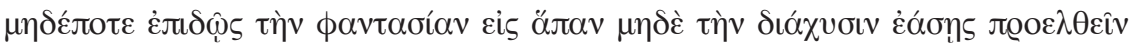

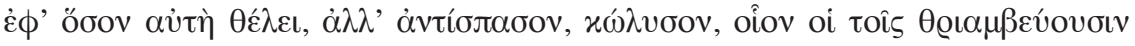

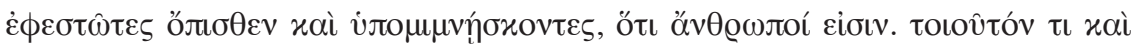

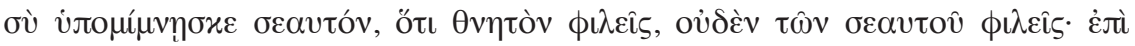

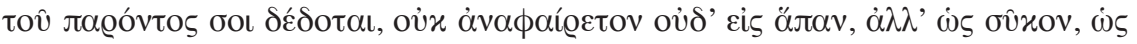

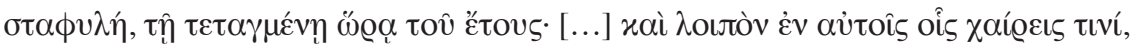

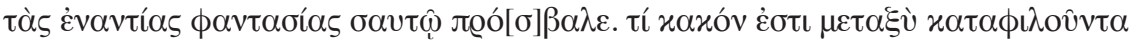

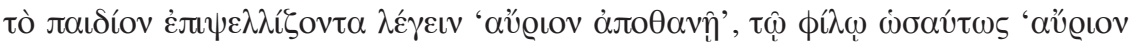

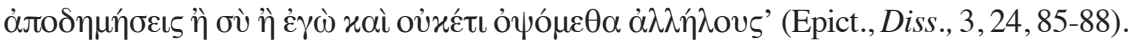

Considero, no obstante, que ninguno de estos dos elementos puede ser aducido como evidencia en contra de la idea de que la indiferencia es la única actitud legítima ante lo indiferente, en la medida en que ni la doctrina del impulso con reservas ni la "cláusula de la fugacidad" implican en modo alguno suspender el carácter absolutamente indiferente del prójimo (o de cualquiera de las cosas exteriores al individuo). Más aún: es preci-

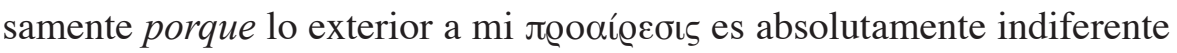
que la cláusula de la reserva o la de la fugacidad pueden no convertirse en motivo de perturbaciones para el individuo que las incorpora en su actitud ante lo exterior. Si esto es así, creo que los pasajes involucrados en las dos doctrinas mencionadas pueden ser presentados como evidencia adicional en favor de la idea de que la indiferencia es la única actitud legítima ante lo indiferente.

\section{Conclusiones}

En las páginas precedentes he sugerido lo siguiente: $i$ ) los pasajes en los cuales Epicteto aborda explícitamente el problema de los indiferentes y de que la distinción entre indiferentes acordes y contrarios a la naturaleza son sumamente ambiguos y parecen ofrecer tres conclusiones divergentes; ii) para comprender la posición definitiva de Epicteto ante este problema debemos complementar el análisis con la lectura de aquellos pasajes que abordan la distinción entre lo que depende y lo que no depende de nosotros; iii) la lectura de esos pasajes arroja como resultado en forma homogénea la idea de que la indiferencia es la única actitud legítima ante lo indiferente; iv) las exigencias (recurrentes en las Dissertationes) de desempeñar adecuadamente nuestros roles sociales y de no descuidar nuestra relación con lo exterior pueden ser comprendidas sin necesidad de suponer que Epicteto 
asigna valor alguno a lo exterior (en este caso, a los otros individuos), en tanto de lo que se trata en ambos casos es de atender a la actitud que adoptamos nosotros ante lo exterior, y no a lo exterior en sí mismo.

Creo que el recorrido propuesto hace evidente que difícilmente podamos encontrar una expresión que sintetice mejor las conclusiones de Epicteto que la frase atribuida por Diógenes Laercio a Aristón: “el fin es vivir con una disposición de indiferencia con respecto a lo intermedio entre la virtud y el vicio, sin renunciar a dicho estado al admitir grados entre ambos, sino estando igualmente dispuesto en relación a todas ellas" ${ }^{59}$ Esto no significa, ciertamente, asumir una influencia efectiva de la obra de Aristón en las reflexiones de Epicteto (lo cual deviene hasta cierto punto secundario), sino simplemente constatar la coincidencia de ambos en cuanto a que exhiben una posición absolutamente heterodoxa respecto del problema de los indiferentes preferidos. Si esto es una consecuencia o, por el contrario, una causa de la apertura doctrinal de Epicteto a las reflexiones de la escuela cínica es algo que, creo, ciertamente amerita una reflexión adicional y que contribuiría a lograr una visión más sistemática de la fuerte interdependencia de las reflexiones de las distintas escuelas helenísticas en el período romano.

\section{BIBLIOGRAFÍA}

Fuentes

[ARrianus] Epicteti Dissertationes ab Arriano digestae ad fidem codicis Bodleiani recensuit Henricus Schenkl, Lipsiae, Teubneri, 1894.

Ioannis Stobaei anthologium, 5 vols., ed. Curtius Wachsmuth \& Otto Hense, Berlin, Weidmann, 1884-1912.

Eicteto, Disertaciones, traducción y notas de Paloma Ortiz García, Barcelona, Gredos, 1993.

Epictetus, The Discourses as Reported by Arrian. The Manual and Fragments, 2 vols., W. A. Oldfather (ed.), London, Loeb, 1961.

_, Discourses. Book I, Robert Dobbin (ed.), Oxford, Oxford University Press, 2008.

_, Discourses and Selected Writings, traducción y comentarios de Robert Dobbin, London, Penguin, 2008.

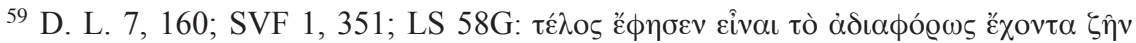

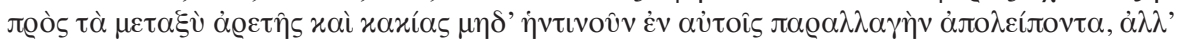

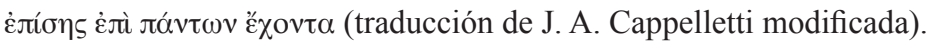


Long, A. A. and D. Sedley (= LS), The Hellenistic Philosophers, 2 vols., Cambridge, Cambridge University Press, 1987.

Los estoicos antiguos. Sobre la virtud y la felicidad, traducción, análisis y notas de Marcelo D. Boeri, Santiago, Editorial Universitaria, 2003.

Los estoicos antiguos, introducción, traducción y notas de Ángel J. Cappelletti, Madrid, Gredos, 1996.

Sexti Empirici opera, vols. 2 \& 3 ( $2^{\text {nd }}$ ed.), H. Mutschmann \& J. Mau (eds.), Leipzig, Teubner, 1914-1961.

Stoicorum Veterum Fragmenta $(=S V F)$, ed. I. von Arnim I/III, Leipzig, Teubner, 1903; Indices, ed. M. Adler, Leipzig, Teubner, 1924.

\section{Estudios}

Bobzien, S., "The Inadvertent Conception and Late Birth of the Free-Will Problem", Phronesis, 43-2, 1998, pp. 133-175.

_, Determinism and Freedom in Stoic Philosophy, Oxford, Clarendon Press, 1998.

BRAICOVICH, R. S., "Critical Assent, Intellectualism, and Repetition in Epictetus", Apeiron, 45, 2012, pp. 314-337.

_., "El solipsismo y el papel de la divinidad en las reflexiones de Epicteto", Pensamiento, 68-255, 2012, pp. 153-161.

_, "Epicteto: el determinismo epistémico y la potencia causal del lógos", Teorema, 302, 2011, pp. 145-156.

_, "Freedom and Epistemic Determinism in Epictetus' Discourses", The Classical Quarterly, 60-1, 2010, pp. 202-220.

_, "La doctrina de las scheseis: observaciones sobre su papel en las reflexiones éticas de Epicteto", Praesentia. Revista Venezolana de Estudios Clásicos, 2012. [En prensa].

_, "La posibilidad de la acción libre en las Disertaciones de Epicteto", Revista de Filosofía (Universidad de Chile), 64, 2008, pp. 17-32.

_, "Proairesis, libertad y liberación en las Disertaciones de Epicteto", Revista de Filosofía (Universidad del Zulia), 58, 2008, pp. 7-22.

BrennAn, T., "Reservation in Stoic Ethics", Archiv für Geschichte der Philosophie, 82-2, 2000, pp. 149-77.

_, The Stoic Life. Emotions, Duties, and Fate, Oxford, Oxford University Press, 2005.

BRunschwig, J., "Sur deux notions de l'éthique stoïcienne. De la réserve au renversement", en G. Romeyer-Dherbey y J.-B. Gourinat (eds.), Les Stö̈ciens, Paris, Vrin, 2005, pp. 357-380.

Dobbin, R., "Prohairesis in Epictetus", Ancient Philosophy, 11, 1991, pp. 111-135.

Dragona-Monachou, M., "Epictetus on Freedom: Parallels between Epictetus and Wittgenstein", en A. S. Mason y T. Scaltsas (eds.), The Philosophy of Epictetus, Oxford, Oxford University Press, 2007, pp. 112-39.

Eliasson, E., The Notion of That Which Depends on us in Plotinus and its Background, Leiden, Brill, 2008.

Frede, M., "A Notion of a Person in Epictetus", en A. S. Mason and Th. Scaltsas (eds.), The Philosophy of Epictetus, Oxford, Oxford University Press, 2007, pp. 153-182. 
GOURINAT, J.-B., "La prohairesis chez Épictète: décision, volonté, ou personne morale?", Philosophie Antique, 5, 2005, pp. 93-133.

GuARIGLIA, O., “¿Qué nos pueden enseñar los estoicos sobre el valor de los valores?", Isegoría, 24, 2001, pp. 205-211.

Hadot, P., La citadelle intérieure. Introduction aux Pensées de Marc Aurèle, Paris, Fayard, 1997.

HaHm, D., “A Neglected Stoic Argument of Human Responsibility”, Illinois Classical Studies, 17, 1992, pp. 23-48.

Inwood, B. "Goal and Target in Stoicism", Journal of Philosophy, 83-10, 1986, pp. 547-556.

_, Ethics and Human Action in Early Stoicism, Oxford, Clarendon Press, 1985.

IRWIN, T. H., "La concepción estoica y la concepción aristotélica de la felicidad", en M. Schofield y Gisela Striker (comps.), Las normas de la naturaleza. Estudios de ética helenística, Buenos Aires, Manantial, 1993, pp. 211-250.

KIDD, I. G., "Moral Actions and Rules in Stoic Ethics", en J. M. Rist (ed.), The Stoics, Berkeley, University of California Press, 1978, pp. 247-259.

_, "Stoic Intermediates and the End for Man", en A. A. Long (ed.), Problems in Stoicism, London, Athlone Press, 1971, pp. 150-72.

Long, A. A., Epictetus. A Stoic and Socratic Guide to Life, Oxford, Clarendon Press, 2002.

Mотто, A. L., "Seneca on Trial: The Case of the Opulent Stoic", The Classical Journal, 61-6, 1966, pp. 254-258.

RIST, J. M., "The Stoic Concept of Detachment”, en J. M. Rist (ed.), The Stoics, Berkeley, University of California Press, 1978, pp. 259-272.

Roskam, G., On the Path to Virtue. The Stoic Doctrine of Moral Progress and its Reception in (Middle-) Platonism, Leuven, Leuven University Press, 2005.

Salles, R., The Stoics on Determinism and Compatibilism, Aldershot, Ashgate, 2005.

SorABJi, R., "Epictetus on Proairesis and Self”, en A. S. Mason and T. Scaltsas (eds.), The Philosophy of Epictetus, Oxford, Oxford University Press, 2007, pp. 87-98.

_, Emotion and Peace of Mind: The Stoic Legacy, Oxford, Oxford University Press, 2000.

STEPHENs, W. O., Stoic Ethics: Epictetus and Happiness as Freedom, London, Continuum, 2007.

Striker, G., "Antípatro o el arte de vivir", en M. Schofield y G. Striker (comps.), Las normas de la naturaleza. Estudios de ética helenística, Buenos Aires, Manantial, 1993, pp. 191-210.

White, N. P. , "Stoic Values”, The Monist, 73-1, 1990, pp. 42-58. 